\title{
Structural studies of titanium and zirconium silicate ion-exchange materials for the treatment of nuclear waste
}

\author{
Jennifer E. Readman \\ School of Natural Sciences, University of Central Lancashire, Preston, UK \\ jereadman@uclan.ac.uk
}

Zeolites are commonly used as ion-exchange materials for the remediation of nuclear waste; however, they have certain drawbacks. Unlike zeolites which contain $\mathrm{SiO}_{4}$ and $\mathrm{AlO}_{4}$ tetrahedra, microporous Ti-silicates can contain $\mathrm{SiO}_{4}$ tetrahedra and $\mathrm{TiO}_{6}$ octahedra and therefore structures are possible which have no traditional aluminosilicate analogues ${ }^{[1]}$. Microporous Ti-silicates such as sitinakite $\mathrm{KNa}_{2} \mathrm{Ti}_{4} \mathrm{Si}_{2} \mathrm{O}_{13}(\mathrm{OH}) \cdot 4 \mathrm{H}_{2} \mathrm{O}$ and the synthetic niobium doped analogue are used for the removal of $\mathrm{Cs}^{+}$and $\mathrm{Sr}^{2+}$ from nuclear waste ${ }^{[2,3]}$. The work presented here will focus on the structures and thermal behaviour of the ion-exchanged $\mathrm{Ti}-$ and $\mathrm{Zr}$-silicates. A clear understanding of both is fundamental in determining if these materials have potential as ion-exchangers within the nuclear industry.

Umbite is a naturally occurring small pore microporous $\mathrm{Zr}$ - silicate, found in northern Russia and synthetic analogues, $\mathrm{K}_{2} \mathrm{ZrSi}_{3} \mathrm{O}_{9} \cdot \mathrm{H}_{2} \mathrm{O}$, can be prepared in the laboratory ${ }^{[4]}$. Ion-exchange studies here have shown that umbite has a preference for common radionuclides, such as $\mathrm{Cs}^{+}$and $\mathrm{Sr}^{2+}$ and $\mathrm{Ce}^{4+}$ (as a surrogate for $\mathrm{Pu}$ ), even in the presence of competing ions. In-situ studies show that these materials behave differently with temperature, indicating that the nature and location of the charge balancing cation plays an important part in determining which high temperature phases are formed and the phases formed do not fit previously reported structures.

Natisite is another material which has interesting ion-exchange chemistry and is a layered $\mathrm{Ti}^{-}$-silicate with the formula $\mathrm{Na}_{2} \mathrm{TiSiO}_{5}{ }^{[6]}$. The structure consists of square pyramidal titanium, with the sodium cations located between the layers. This coordination environment is highly unusual for Ti. Inclusion of zirconium or vanadium in the framework has a considerable effect on the ionexchange properties, with changes in the exchange capacity and the rate of uptake for certain ions of interest.

A combination of techniques to probe long and short-range order (PDF and XAS) have been used to understand the ion-exchange and thermal behaviour of these materials.
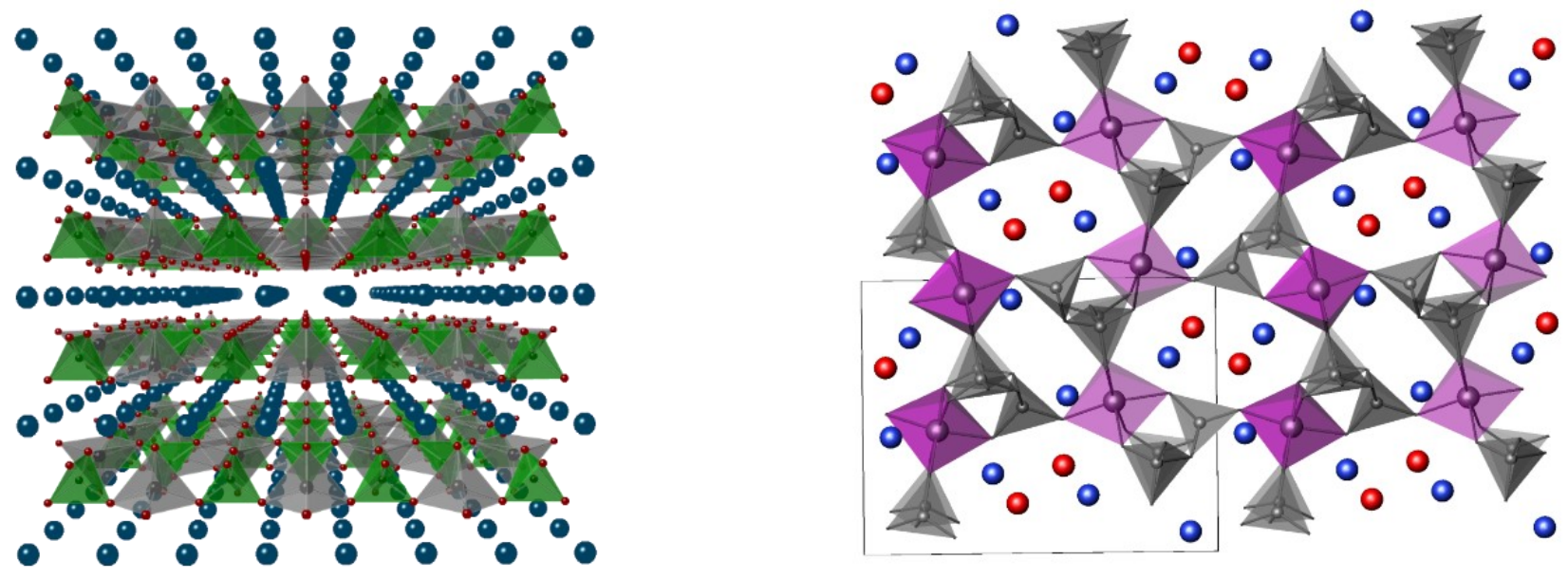

Figure 1. Structural representation of umbite (right) and natisite (left).

1. P. A. Wright, Microporous Framework Solids, The Royal Society of Chemistry, Cambridge, 2008.

2. D. M. Poojary, et al., Chem. Mater., 6, 2364 (1994).

3. A. Tripathi, et al., J. Solid State Chem., 175, 72 (2003).

4. D. M. Poojary, et al., Inorg. Chem., 36, 3072 (1997).

5. A. Ferreira, et al., J. Solid State Chem., 183, 3067 (2010).

6. D.G. Medvedev et al., Chem. Mater., 16, 3659 (2004).

Keywords: Zeotype, ion-exchange, titanium, zirconium 